\title{
The Changes Needed in Teaching Training Regarding Participatory Era [Digital Age]
}

\author{
Umut Kisa
}

\begin{abstract}
Teaching training has taken different forms since the onset of formal learning at different levels. Teachers play a very significant role in the transfer of information to learners. This paper analyzes the fundamentals of learning at the digital age and all that comes with it. The primary purpose of this research is to attempt to answer the questions:

1. The transformation of digital and participatory culture.

2. Evaluation of convergence in terms of the education needs of students.

3. How to transform teacher education.

4. Why are these changes necessary?

5. Consequences of the changes.

These parts will assist in coming up with the basic design of this paper. Through analysis, major findings are displayed as part of the transformational designs of the work. Education takes a broad perspective of life as it acts as a tool for transferring learned information from one generation to the next in order to keep the training process active. The ICCSE-International Conference on Computer Science and Education is one of the bodies that seek to help in the transformation of the digital age. Learning as a process should equip students with resources, information, and development of skills at different levels. Teaching training during the participatory era is a phase of learning where most of the classwork is student based-the teacher is not seen as the main source of information but an individual who makes understanding of the learning process. Learning at this age again has become digital such that students are able to get informational materials digitally. This paper is therefore prepared for the digital age to help understand the findings of the participatory era of learning.
\end{abstract}

Index Terms-Participatory Era, Digital Transformation, Culture and Convergence Culture.

\section{INTRODUCTION}

Teaching training has taken different forms considering the ancient learning processes until this digital age. We must ask thought-provoking questions: 1) Why are we in classrooms? 2) Why there is a higher-level person in a class? 3)Why cheating in class is forbidden? 4)Why do we have seats in a row and staring at one person? 5) Why are the students being not teachers as teaching is one of the best methods to learn. When humanity finds some solution to a problem, we have a tendency to freeze our thoughts [1]. When needs changed, it could be hard to see what needs to change to adapt. We are in a new and completely different environment. Participatory era requires an active learning environment where the students openly participate in what goes on. The new era requires new digital skills namely Play, Performance, Simulation, Appropriation, Multitasking, Distributed Cognition, Collective Intelligence, Judgement, Transmedia Navigation, Networking, Negotiation [2].

Revised Version Manuscript Received on 10, September 2019.

Umut Kisa, Bilgi University, Kazım Karabekir, Eyüp/İstanbul, Turkey

(Email: umutkisa@solaunitas.com)
The studies, research, and learners at a greater percentage should contribute to outcome stages. [3]. Digital transformations have highly contributed to the learning processing by equipping the students with appropriate tools of study enabling them to enjoy and appreciate learning as a process. Henry Jenkins in his scholarly articles introduces the art of convergence culture and how it creates similarity to the digital age learning era [4]. The digital age requires innovation, creativity and computer techniques which will enable both the teachers and the learners to be at par with these 21st-century academic trends. In his 2008 journal, Jenkins explains the transition of media and how information has transcended since the academic era began. Convergence culture has been in play from the time learning started. The biggest task that is left for scholars is to find a way to better research methods and to be able to make media a tool that is able to pass the right information to the students. Besides, culture can be easily passed from one generation to another and the media can play this role by equipping the mass with the right information. Teaching training participatory can be done when these vices are incorporated through sports and language. A given group with diverse beliefs can be put together understudy for some time, and as time progresses, their different ideas are converged as one [5]. This practice yields a common goal of learning from different personalities and through research, Jenkins confirms that this has been fruitful in the training field. Technology is a great contributor to the digital age. Trainers are required to understand and be well updated on such transitions.

\section{DIGITAL TRANSFORMATION AND PARTICIPATORY CULTURE}

Education started as a formal transfer of information from the trainers to the trainees. Somebody living in the $80 \mathrm{~s}$ cannot compare the recent changes that have taken place to this age. The cinemas of the 80s cannot match what we see today. The transformation has taken place over a period. During this era of change, there is a lot that took place. The computers that were used as the era of computers came were slow and had many errors in running the workload. This analog period had setbacks that put a lot of negative outcomes to the academic field. The time then came when computers were improved and things happened faster with more work being produced [7]. This is the digital age which has brought about a quick change and the final transformation. At this age, the world has become a global village where information can be

\section{Published By:}

Blue Eyes Intelligence Engineering

\& Sciences Publication 
accessed faster and any time by anybody as long as one is closer to the internet. [8]. Participatory culture has been introduced at this age. Students not only act as the consumers but also the producers. The information has become too easy to come by through digital media like internets and other sources making the learners to also have the power to come up with ideas that they learn on their own. In the event of mutual sharing of information, the teaching training process becomes efficient since the teacher will provide the basis of the study and the student will use that background to come up with a proper way of understanding what is required of them.

\section{CONVERGENCE CULTURE AND STUDENT NEEDS}

The joining of old and new ideas in order to make a media that gives information on both scenarios is all that converging culture entails. Cultural process of consumption and creation of such a media required a process of transition and as Jenkins puts it-old ideas created the new ones by putting in the ideas in media and giving information that appeals to the students. Students have several needs on their part [9] if they are made participants of the process, they will be able to contribute to the result of the process of converging media to give a unified platform in which students can utilize everything. Learning is made better when opinions are taken from the teachers and students and a media convergence is made such that one does not know where it started or where it ends [10]. Most students will learn faster in such an environment where participation is allowed, the participants become free to contribute and at the end build a media that contains information that can feed all the categories of persons.

\section{TRANSFORMATION OF TEACHER EDUCATION}

Transforming of teaching is not necessarily changing how things are done or fixing problems associated with education but rather taking the work teachers do and making it exceptional. There are several possibilities that can be explored by teachers in a safe and constructive way. As the modern world shifts, teaching is transformed so it is important to note that teaching is transformed every time. Terry the director of Teach Thought had plenty of classroom experience to draw on for his work. He says that we must take position action in order to transform education and teacher based digital learning. [11]. To maintain teacher education learning it is important to consider the following; starting small, starting now, taking learning as a system, reflecting on transformations, listening to students, collaborating, staying curious and celebrating learning as a process. These factors reality. Teachers have a critical role in learning as they help students not only in knowledge acquisition but also the selection of appropriate digital resources for research, presentation, and analysis. Furthermore, a teacher can promote the use and innovation of technologies through their attitude. Hence, the transformation of a society to that which values technology is dependent on instructors. Professional training in the application of technologies in teaching is founded on research which shows that effective learning can act as a fueling drive to making teaching transformation a

involves participation through which parties take part in projects and activities, share tasks, and communicate creatively. Teachers that have not been trained through participatory culture precepts are not effective educators in the digital era as they may not promote mutual learning and sharing of knowledge. Transformational training for educators should involve various attributes that foster participatory culture. Otherwise, the current practices show the gap between the ideal learning in the world and schools as it is different between the former and new one. Teachers should be concerned with students who do not demonstrate amplification of their experiences in schools after using technological tools. Additionally, the educators should be equipped with skills to measure the differences between the students that utilize digital media as a tool for learning and those who use it primarily for social communication and entertainment. The students that can relate digital media with their experiences have an advantage over others who only rely on the traditional structures for learning.

While most of the students who have exemplary skills in modern media learn them from their parents, these skills help them in academics and career development. Similarly, teachers can help their children in attaining these skills, which are useful in both academic and professional aspects. Knowledge sharing associated with digital media has been proven helpful in innovations as it engages many students [11]. Even though digital media plays a critical role in enhancing both personal attributes and professional skills, inefficiency in domain learning, which is caused by lack of proper teachers' training, continues to enlarge the gap in terms of reduced participation, reflecting social inequality. Teacher training is fundamental in bridging the gap between children of different backgrounds as educators can facilitate knowledge sharing.

One of the fundamental training that teachers require is bridging the gap between the digital world and school as it has been a challenge to relate the two as well as link the activities involved. This gap can be intentionally bridged by matching the corresponding activities in both aspects.

New media environments and traditional needs of a school can be matched without the invention of new approaches to learning and teaching as long as educators identify their corresponding affordances. While the activities used outside the school may be unrelated, learned skills in digital media can be utilized to solve problems or questions in schools. Some of the skills may be learned from outside school, but their application can be useful in learning domains. Hence, tools such as youth media arts organizations, fantasy sports, citizen science, video games, and maker-spaces can be utilized to define educational benefits [13]. From this perspective, learning involves not only the curriculum requirements but real-world knowledge, which can be applied in the future. This transformation does not necessarily require new teaching approaches but the integration of the in- and out- of school learning in the precepts of participatory culture. 
Educators should be mandated with the responsibility of ensuring that teacher trainees utilize participatory concepts in the higher learning institutions as the subsequent learning would be utilized in professional practices. It is essential for the policymakers and education leaders to get involved in designing digital curriculum as the current frameworks can hinder the perceived learning. Even in digital environments and related learning, the education domain focuses on standardized tests, which may not be the exact measure of the knowledge acquired [6]. Therefore, defining learning in terms of standardized tests can be a poor measure as it captures only a single perspective, which measures in-school benefits of digital tools. The implication is that students' performance and achievement in the educational domain is insufficient.

Participatory learning is founded on behaviorism and social learning, which are traditional theories that explain how human beings learn either intellectually or habitually. Hence, it promotes collaboration as a tool to achieve the desired education outcomes. In the digital era, collaboration can be defined under varied dimensions, including social networks, knowledge sharing, and educational partnerships. Teachers that are trained in digital tools for learning and collaboration involve their students, making them participate in diverse activities, such as discussions and content generation.

Teachers training should entail technological tools for content creation. However, a significant number of teachers, especially those that have not been trained in digital communication, lack fundamental concepts that are useful to their learners [8]. Such teachers do not promote content creation and their perception of participation in the digital era is vague. As a result, they fail in their mandate as educators. They are limited as they may not help their audience with active participation techniques. Based on such challenges, the transformation of teachers training in the digital era is essential as it helps to raise a generation that not only communicates creatively but also utilize technological tools in knowledge sharing and learning.

Primarily, transformation in teachers training is necessary as the dynamic society requires educators that can help the new generation of learners to acquire new skillsets and knowledge to build a better world. Since technology is essential in the development of all sectors, equipping students with solid foundations to rely on it for their endeavors is critical. Teachers that are well equipped with technological knowledge can easily help learners to sharpen their innovative skills.

\section{NECESSITY OF EDUCATION CHANGES \& RESULTS}

As we learn the importance of digital age it is also in order to get reasons or rather understand why we so much need the changes. Old things sometimes wear out and may lose meaning and taste, it is, therefore, important to introduce new changes in a system to find out if there can lead progress. Education changes as been put herein earlier does not mean pulling out wrongs but rather adding more taste to the experience that the teachers have amassed in the classrooms in order to make the process more better than what has been there. The teachers have to be computer literate since the age we are in requires such a skill. A teacher should be able to assemble technological tools in the preparation of a lesson to make the lesson more interesting to the students. This makes learning more student based and gives the teacher an environment to improve on areas where the emphasis is needed.

\section{CONSEQUENCES OF EDUCATION CHANGES}

In most cases, education policymakers get a lot of problems when it comes to the issue of educational changes. It is not easy for them to delete all the beliefs of a given culture and start teaching new ideas. The old ideas must be preserved, and the new ones put in place in a systematic way such that in the end what remains is a converged culture. This process may be long and tiresome as it may take centuries before the real change is realized. In order to see the positive impact of the changes, a great deal of time must be invested in the changes. This has given a challenge to yielding faster results on education.

Promotion of digital spaces and participatory culture may render the professional practice of teachers less useful. One of the fears of educators is that resultant practices of digital era transformation may render them unimportant or obsolete in a classroom setting [13]. Similarly, the personnel that is mandated with collecting and classifying relevant information in a school set up feel by-passed as learners use search engines and online resources that are not reviewed. Another threat is that learners may think that experts are not necessary. Thus, the professional practice of teachers and educational content developers may be rendered less useful, and learners may regard them as unimportant or unnecessary.

Another consequence of transformation with regard to participatory learning and culture is that the relationship among students and the role of the teacher may change.

Transformation of teachers training in the digital era should be aligned to personal interests as well as educational needs. While affiliations demonstrate interests among students, participatory culture should cultivate beneficial interactions not only for social but also intellectual learning. It is the responsibility of the instructors to ensure that the students participate in productive activities through regulation and mentorship [4]. As teachers assess the applicability of the gained knowledge, other factors, such as teamwork and practical attributes of the media spaces, should be examined.

Most importantly, learning domains should be considered in all aspects, whether psychomotor, cognitive, or affective. It is therefore critical to deliberate on the implications of each activity and determines whether it's useful in skills development and learning process. Educators should develop activities that contribute to learning in all domains. Thus, the training provided to the teachers should be wide, and the trainers should help them to learn the development of tasks that cover all areas of learning and students' needs. Besides, they should link the learned skills with professional development in such areas as communication, teamwork, collaboration, and innovation [14]. To effectively transform educational systems in the digital era, there is a need for 
cooperation among the stakeholders to develop an effective framework for teachers training based on participatory culture without overlooking student needs.

As education systems and resources change due technological innovations, teachers' involvement in the transformation from the traditional school system to the participatory model in the new media spaces will yield better results as well as uniformity in learning. Additionally, one of the important roles that teachers can play in contemporary school design is guiding content development and knowledge acquisition, which are useful for future academic work and professional development. Most importantly, ubiquitous learning should be promoted in all educational domains as it fosters creativity and innovation. While the Internet provides mechanisms for learning and communication in the digital era, it erodes cultural values and identity. It can also positively influence the students by helping them to work with diverse individuals and teams. Thus, teachers' training transformation to effectively promote digital learning and participatory culture is beneficial for the corresponding students and communities.

\section{REFERENCES}

1. Gee, J. P., The Anti-Education Era: Creating Smarter Students through Digital Learning, St. Martin's Griffin (January 8, 2013), E-Book Version

2. Jenkins, H., Purushotma, R., Weigel, M., Clinton, K., \& Robison, A. J. (2009). Confronting the challenges of participatory culture: Media education for the $21 \mathrm{st}$ century. MIT Press.Retrieved from https:// www.curriculum.org/ secretariat/files/Sept20TLConfronting.pdf

3. Jayendrakumar N., A., Redefining the role of teachers in the digital era, The International Journal of Indian Psychology, vol. 3 no. 3, pp. 41-45, 2016.

4. Tombleson, Bridget, and Katharina Wolf, "Rethinking the circuit of culture: How participatory culture has transformed cross-cultural communication," Public Relations Review, vol. 43, no. 1, pp. 14-25, 2017.

5. Borthwick, Arlene C., and Randall Hansen, "Digital literacy in teacher education: Are teacher educators competent?" Journal of Digital Learning in Teacher Education, vol.3, no.2, pp.46-48, 2017.

6. Meyers, Eric M., Ingrid Erickson, and Ruth V. Small, "Digital literacy and informal learning environments: An introduction," Learning, Media and Technology, vol. 38 no. 4, pp. 355-367, 2013.

7. Dom $\tilde{A}$-nguez, Roberto G., "Participatory learning," Encyclopedia of the Sciences of Learning, pp. 2556-2560, 2012.

8. Deodato, Joseph, "The patron as producer: Libraries, Web 2.0, and participatory culture," Journal of Documentation, vol. 70 no. 5, pp. 734-758, 2014.

9. Leal Filho, W., S. Raath, B. Lazzarini, V.R. Vargas, L. de Souza, R. Anholon, O.L.G. Quelhas, R. Haddad, M. Klavins, and V.L. Orlovic, "The role of transformation in learning and education for sustainability," Journal of Cleaner Production, vol. 199, pp. 286-295, 2018.

10. Dena, Christy, "Emerging participatory culture practices," Convergence: The International Journal of Research into New Media Technologies, vol., 14 no. 1, pp. 41-57, 2008.

11. Sappey, Jennifer, and Stephen Relf, "Digital technology education and its impact on traditional academic roles and practice," Journal of University Teaching \& Learning Practice, vol. 7, no. 1, 2010.

12. Waldron, Janice, Roger Mantie, Heidi Partti, and Evan S. Tobias, "A brave new world: Theory to practice in participatory culture and music learning and teaching," Music Education Research, vol. 20, no.3, pp. 289-304, 2017.

13. Jenkins, Henry, Mizuko ItoÌ and Danah Boyd, Participatory Culture in a networked era, Hoboken, Wiley, 2015.

14. Fenwick, Tara, and Richard Edwards, "Exploring the impact of digital technologies on professional responsibilities and education," European Educational Research Journal, vol. 15 no. 1, pp. 117-131, 2015.

15. Bridges, DianeR., Richard A. Davidson, Peggy Soule Odegard, Ian V. Maki, and John Tomkowiak, "Interprofessional collaboration: three best practice models of interprofessional education," Medical Education Online, vol. 16, no. 1, pp. 6035, 2011.

16. Thomas, Paul, "Wikipedia and participatory culture: Why fans edit", Transformative Works and Cultures, vol. 22 2016. 